\title{
How do medical students and doctors learn clinical endocrinology?
}

\author{
Mehul Patel and Maralyn Druce \\ Barts and the London School of Medicine and Dentistry
}

\begin{abstract}
Introduction:
Little research has been conducted into methods of learning clinical endocrinology amongst students and doctors. Exposure to diabetes and endocrinology is not compulsory at all medical schools. Senior clinicians feel that final year medical students' knowledge and exposure of endocrinology is insufficient ${ }^{1,2}$. Trainee doctors have reported a lack of confidence in managing diabetes and felt their undergraduate and postgraduate training had not prepared them adequately ${ }^{3}$. Given increasing demands of medical schools to deliver a broad and varied curriculum alongside the increasing service demands of junior doctors there is a need to establish new and innovative learning resources.
\end{abstract}

\section{Aims:}

1. To identify the perceived usefulness of different learning resources employed by students and doctors currently engaged in endocrine practice.

2. To identify untapped teaching methods for clinical endocrinology

\section{Method:}

\section{Procedure:}

- Prospective pilot study

- Medical students, junior doctors and consultants currently engaged in endocrine medicine completed a paper / online questionnaire.

- The questionnaire determined the perceived usefulness of potential educational resources for clinical endocrinology.

- Participants were recruited via convenience sampling.

\section{Participants:}

Medical students at Barts and the London School of Medicine:

- $3^{\text {rd }}$ year medical students $(N=57)$

- Final year medical students $(\mathrm{N}=4)$

Doctors employed in endocrine teams at Barts Health:

- Grade $\mathrm{F} 1-\mathrm{CT} 2(\mathrm{~N}=3)$

- Registrar ( $\mathrm{N}=5)$

- Consultant $(\mathrm{N}=8)$

\begin{tabular}{|c|c|c|c|c|c|c|}
\hline Results: \\
\hline Learning Resource & $\begin{array}{c}\text { Not } \\
\text { Applicable }\end{array}$ & $\begin{array}{c}\text { Very } \\
\text { Unhelpful }\end{array}$ & Unhelpful & Neutral & Helpful & $\begin{array}{c}\text { Very } \\
\text { helpful }\end{array}$ \\
\hline Lectures (all participants) & $3.9 \%$ & $3.9 \%$ & $0.0 \%$ & $3.9 \%$ & $62.3 \%$ & $26.0 \%$ \\
\hline Textbooks (all participants) & $7.8 \%$ & $3.9 \%$ & $2.6 \%$ & $19.5 \%$ & $48.1 \%$ & $18.2 \%$ \\
\hline Patient Encounters (all participants) & $54.0 \%$ & $0.0 \%$ & $0.0 \%$ & $5.3 \%$ & $13.2 \%$ & $27.6 \%$ \\
\hline $\begin{array}{c}\text { Patient Encounters (excluding 3rd year } \\
\text { students) }\end{array}$ & $0.0 \%$ & $0.0 \%$ & $0.0 \%$ & $0.0 \%$ & $20.0 \%$ & $80.0 \%$ \\
\hline
\end{tabular}

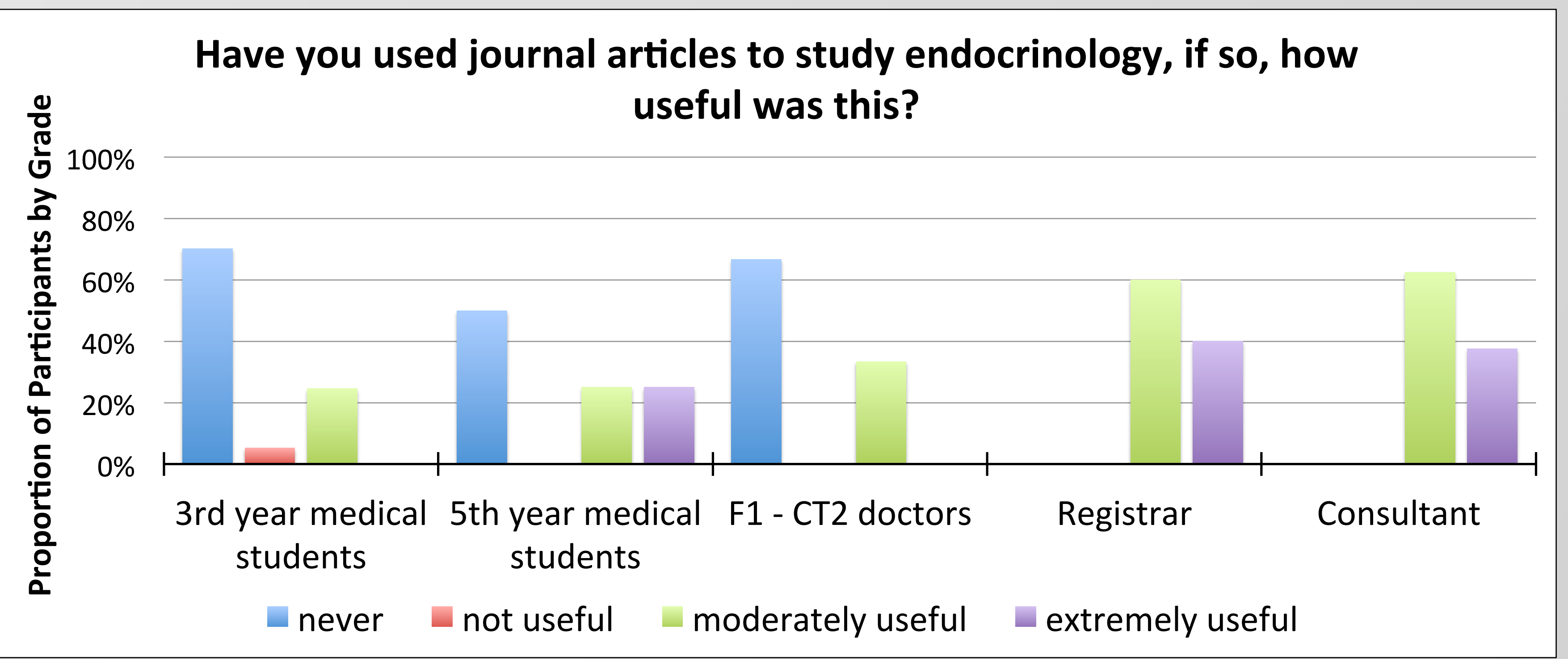

Have you used e-learning modules, if so, how useful was this?

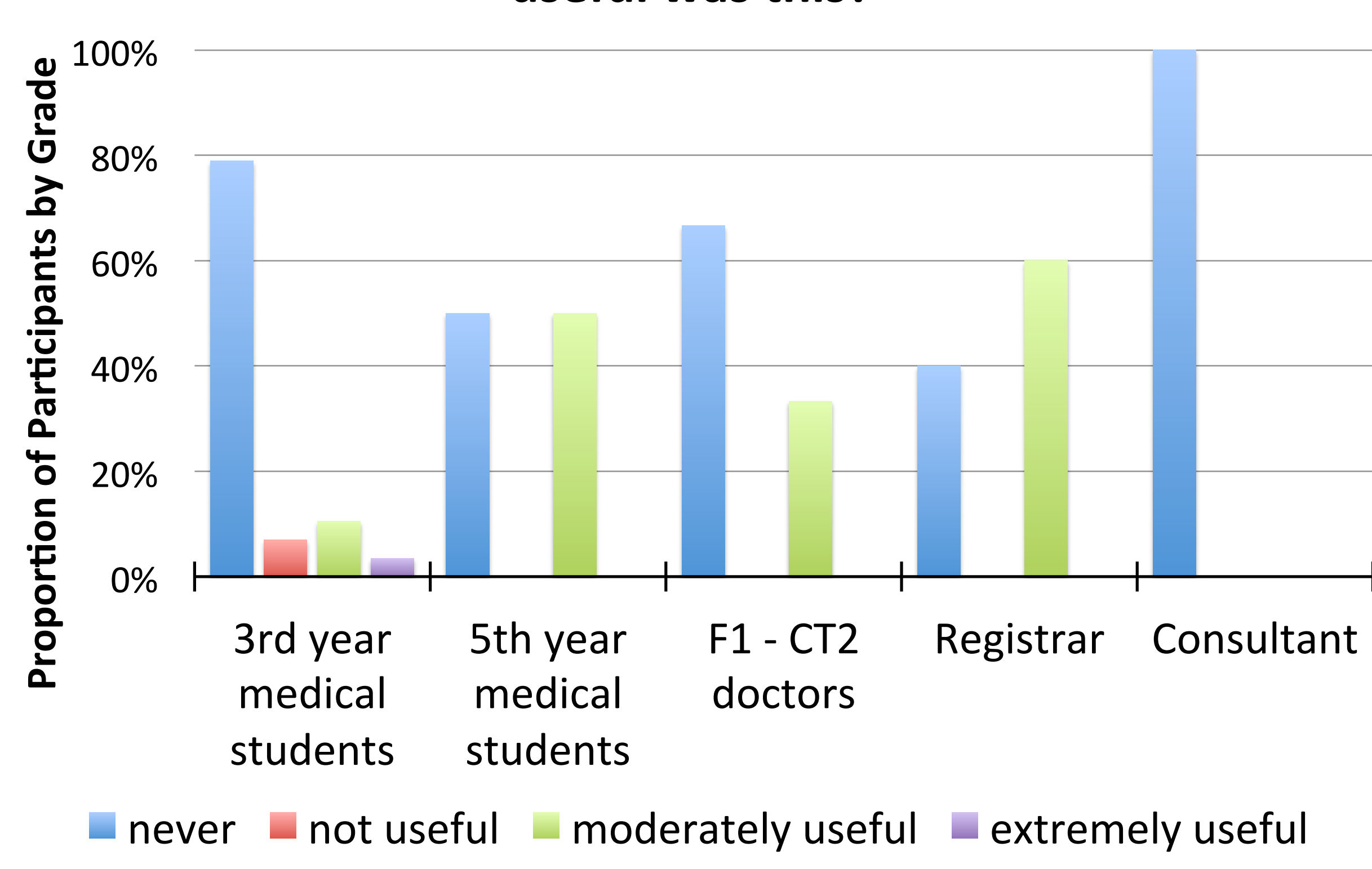

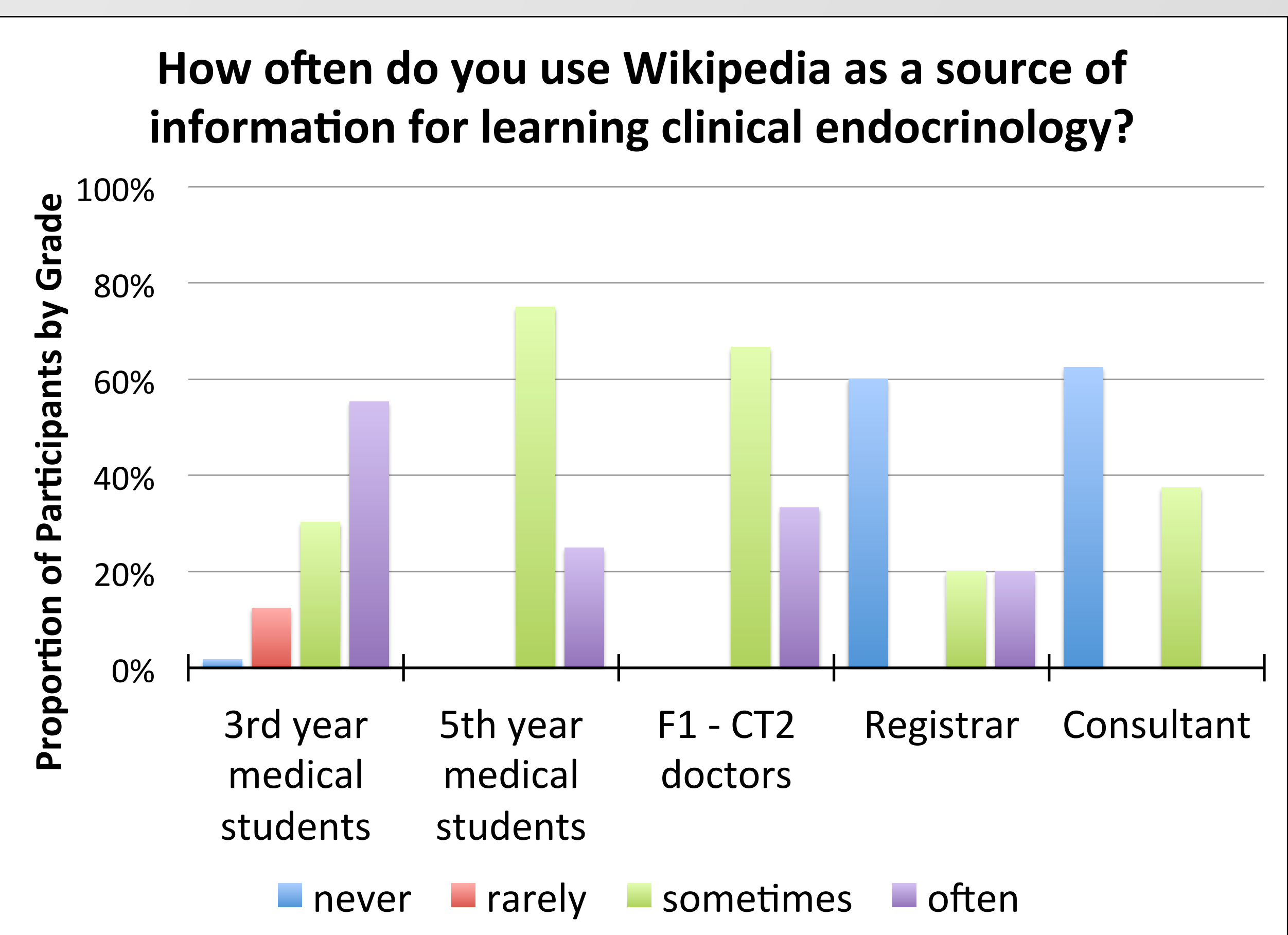

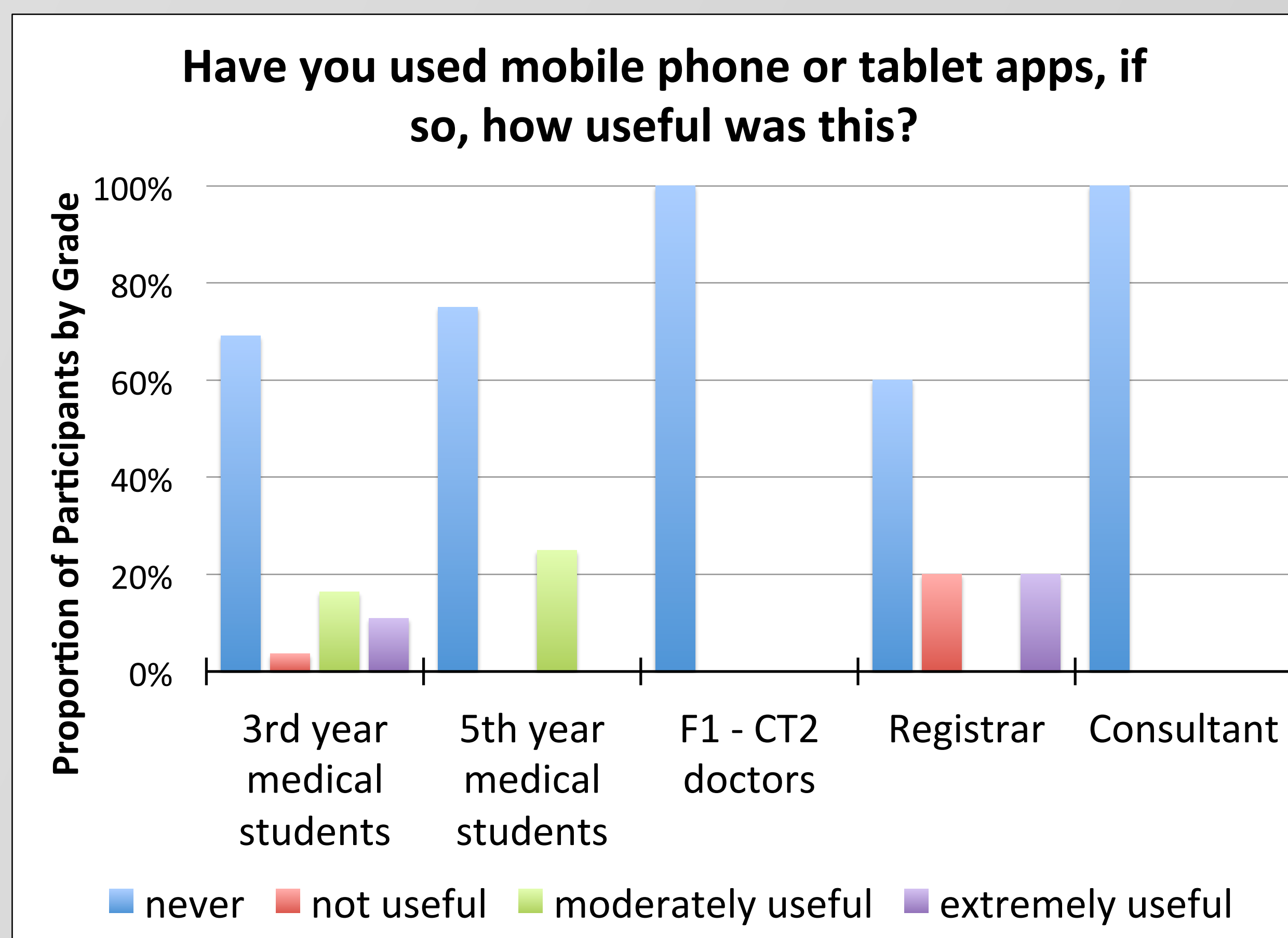

'I tunes $U$ ' and podcasts had never been used by $93.5 \%$ of participants

Student Comments: Students would be willing to use e-learning resources and podcasts if directed to appropriate sources

\section{Conclusion:}

- Traditional methods (lectures, textbooks and patient encounters) are popular and helpful learning resources for both students and doctors.

- E-learning modules, podcasts and mobile phone / tablet 'apps' are relatively unexploited tools, however, the minority of participants who utilised these methods did find them useful.

- Perceived usefulness is a starting point for designing and evaluating gradespecific educational resources.

\section{Recommendations:}

- Findings need to be validated by a study with larger numbers of participants across different grades.

- Designing 'virtual patients' may help students and junior doctors to further their clinical skills in Endocrinology.

- Senior clinicians may benefit from podcasts as a bite size method of delivering the latest clinical developments. 